\title{
Article
}

\section{Motivational and behavioural models of change: A longitudinal analysis of change among men with chronic haemophilia- related joint pain}

Elander, J, Richardson, Cassandra, Morris, J, Robinson, G and Schofield, M B

Available at http://clok.uclan.ac.uk/17699/

Elander, J, Richardson, Cassandra ORCID: 0000-0003-1208-6588, Morris, J, Robinson, $G$ and Schofield, M B (2017) Motivational and behavioural models of change: A longitudinal analysis of change among men with chronic haemophilia-related joint pain. European Journal of Pain, 21 (8). pp. 13841396. ISSN 1090-3801

It is advisable to refer to the publisher's version if you intend to cite from the work. http://dx.doi.org/10.1002/ejp.1040

For more information about UCLan's research in this area go to http://www.uclan.ac.uk/researchgroups/ and search for <name of research Group>.

For information about Research generally at UCLan please go to http://www.uclan.ac.uk/research/

All outputs in CLoK are protected by Intellectual Property Rights law, including Copyright law. Copyright, IPR and Moral Rights for the works on this site are retained by the individual authors and/or other copyright owners. Terms and conditions for use of this material are defined in the policies page. 
Motivational and behavioral models of change: a longitudinal analysis of change among men with chronic hemophilia-related joint pain

J. Elander ${ }^{a}$, C. Richardson ${ }^{b}$, J. Morris ${ }^{c}$, G. Robinson ${ }^{d}$, and M.B. Schofield ${ }^{a}$.

a) Centre for Psychological Research, University of Derby, Derby UK

b) School of Psychology, University of Central Lancashire, Preston, UK

c) Haemophilia Society UK, London, UK

d) Department of Psychology, London Metropolitan University, London, UK

Correspondence: James Elander, Centre for Psychological Research, University of Derby, Kedleston Road, Derby DE22 1GB, UK. Email j.elander@derby.ac.uk

Cite as:

Elander, J., Richardson, C., Morris, J., Robertson, G. \& Schofield, M.B. (2017). Motivational and behavioral models of change: a longitudinal analysis of change among men with chronic haemophiliarelated joint pain. European Journal of Pain, 21 (8), 1384-1396. DOI:10.1002/ejp.1040

\begin{abstract}
Background: Motivational and behavioral models of adjustment to chronic pain make different predictions about change processes, which can be tested in longitudinal analyses.

Methods: We examined changes in motivation, coping and acceptance among 78 men with chronic hemophilia-related joint pain. Using cross-lagged regression analyses of changes from baseline to 6 months as predictors of changes from 6 to 12 months, with supplementary structural equation modelling, we tested two models in which motivational changes influence behavioral changes, and one in which behavioral changes influence motivational changes.

Results: Changes in motivation to self-manage pain influenced later changes in pain coping, consistent with the motivational model of pain self-management, and also influenced later changes in activity engagement, the behavioral component of pain acceptance. Changes in activity engagement influenced later changes in pain willingness, consistent with the behavioral model of pain acceptance.

Conclusions: Based on the findings, a combined model of changes in pain self-management and acceptance is proposed, which could guide combined interventions based on theories of motivation, coping and acceptance in chronic pain.
\end{abstract}

Keywords: Chronic pain; change processes; motivation; coping, acceptance, hemophilia. 


\section{Introduction}

Models of adjustment to chronic pain emphasize either motivational or behavioral processes as drivers of change. The change processes involved in three such models are illustrated in Fig. 1 . In the motivational model of pain self-management, motivation to self-manage changes first, and this then influences coping and other self-management behaviors (Jensen et al., 2003a). There is evidence of concurrent associations between motivation to self-manage and coping (Jensen et al., 2003b, 2004), but no longitudinal tests to our knowledge of the model's key prediction that motivational changes influence later changes in coping behaviors. The first aim of the present study was therefore to test whether changes in motivation to self-manage influence later changes in pain coping and other selfmanagement behaviors.

Figure 1. Change processes in three models of adjustment to chronic pain

\begin{tabular}{|l|l|}
\hline $\begin{array}{l}\text { Motivation } \\
\text { Increased motivation }\end{array}$ & $\begin{array}{l}\text { Behavior } \\
\text { Increased coping and other } \\
\text { ('readiness') to self-manage }\end{array}$ \\
\cline { 2 - 2 } &
\end{tabular}

A. The motivational model of pain self-management (Jensen et al., 2003a)

\begin{tabular}{|l|l|}
\hline $\begin{array}{l}\text { Behavior } \\
\text { Increased behaviors in } \\
\text { pursuit of valued goals while } \\
\text { in pain (activity engagement) }\end{array}$ & $\begin{array}{l}\text { Motivation } \\
\text { Reduced motivation to avoid } \\
\text { and control pain (pain } \\
\text { willingness) }\end{array}$ \\
\hline
\end{tabular}

B. The behavioral model of pain acceptance (Vowles et al., 2014)

\begin{tabular}{|l|l|}
\hline $\begin{array}{l}\text { Motivation } \\
\text { Reduced motivation to avoid } \\
\text { and control pain (pain } \\
\text { willingness) }\end{array}$ & $\begin{array}{l}\text { Behavior } \\
\text { Increased behaviors in } \\
\text { pursuit of valued goals while } \\
\text { in pain (activity engagement) }\end{array}$ \\
\cline { 2 - 3 }
\end{tabular}

C. The motivational model of pain acceptance (Kranz et al., 2010)

Pain acceptance is increasingly recognized as a key process in improved adjustment to chronic pain. It involves a motivational dimension ranging from 'controlling pain' to 'pain willingness' and a behavioral dimension ranging from 'pain costs' to 'engagement in activities other than pain control' (Lauwerier et al., 2015). Pain willingness involves accepting that trying to avoid or control pain can be counter-productive, and activity engagement involves continuing with life activities in spite of pain. Both elements are measured by the Chronic Pain Acceptance Questionnaire (CPAQ) (McCracken et al., 2004).

The behavioral model of pain acceptance emphasizes behavioral change as the driver in processes leading to improved adjustment. This model is based on acceptance and commitment therapy 
(ACT), which focuses on the context and function of behavior (Hayes, 2004, 2006); "The focus of ACT for chronic pain is on assisting pain sufferers to engage in a flexible and persistent pattern of valuesdirected behavior while in contact with continued pain and discomfort" (Vowles et al., 2014, p. 390).

This model predicts that behaviors change first, which then leads to changes in motivation or attitude, so changes in activity engagement should influence subsequent changes in pain willingness. For example, a cross-sectional cluster analysis identified a group with high scores for activity engagement and low scores for pain willingness, but no group with the opposite pattern, suggesting that "activity engagement is necessary but not sufficient for pain willingness" (Vowles et al., 2008, p. 289).

The motivational model of pain acceptance emphasizes motivational change as the driver of change. It is based on self-regulatory theory, which focuses on disengagement from blocked goals and re-engagement with more adaptive goals (Lauwerier et al., 2015). This involves disengaging from the goals of controlling or avoiding pain, and re-engaging with other goals and activities (Van Damme et al., 2008), which requires a motivational shift "from symptom reduction to valued living" (Wicksell et al., 2009, p. 760).

This model predicts that motivation changes first, which then leads to changes in behaviors, so changes in pain willingness should influence subsequent changes in activity engagement. For example, in a cross-sectional study, the influence of pain willingness on positive affect was mediated by activity engagement, suggesting that change in pain acceptance was "an attitudinal-behavioural process" and "a sequence leading from pain willingness (which primarily terminates negative affect) to activity engagement (which additionally produces positive affect)" (Kranz et al., 2010, p. 1024). From that perspective, the cluster of people with high scores for activity engagement and low scores for pain willingness reported by Vowles et al. (2008) "might have taken the second step towards pain acceptance (i.e., activity engagement) before the first one (i.e., pain willingness) - which might have let them stumble, so to speak" (Kranz et al., 2010, p. 1024).

The behavioral and motivational models of pain acceptance therefore make different predictions about how changes in pain willingness and activity engagement should influence one another, and the second aim of the present study was to test those predictions. We therefore tested three hypotheses based on the models illustrated in Fig. 1:

1. Changes in motivation to self-manage pain influence later changes in pain coping and selfmanagement behaviors.

2. Changes in activity engagement influence later changes in pain willingness.

3. Changes in pain willingness influence later changes in activity engagement.

\section{Methods}

Overview

The study is a secondary analysis of longitudinal data from people with hemophilia, a condition in which repeated bleeding into joints leads to arthropathy and chronic joint pain (Riley et al., 2011; Witkop et al., 2012), causing similar suffering and impairments as in other chronic pain conditions (Humphries \& Kessler, 2015, 2016). In the primary study, participants were all sent a booklet and DVD about chronic joint pain. The booklet gave information about types of pain, the impact of pain, pain medications, and the benefits of activity and exercise. The DVD featured people with hemophilia talking about their experiences of living with joint pain. The booklet and DVD were designed as motivational 
materials to increase readiness to self-manage chronic pain. They did not give instruction in skills or techniques, and were posted to participants with no personal contact or interaction with health professionals as part of the study.

One group was sent both the booklet and DVD at baseline, the other was sent the booklet at baseline and the DVD after six-month follow-up. This design allowed the impact of the DVD to be assessed at six months, and both groups to be combined for longitudinal analysis at 12 months. At sixmonth follow-up, the DVD increased readiness to self-manage pain, but had no effect on coping or acceptance (Elander et al., 2011). Baseline and six-month data showed that changes rather than baseline values were the best predictors of improved outcomes (Elander et al., 2013). The present analysis therefore focused on the effects of changes from baseline to six months on changes from six to 12 months, using cross-lagged panel analyses to test specific causal sequences.

\section{Participants}

The initial sample comprised 209 men with hemophilia who began the primary study described above. The inclusion criteria were diagnosed hemophilia, age over 18 years, and giving consent to take part. The exclusion criteria were serious co-occurring medical conditions or not giving consent. Ages ranged from 20 to 84 years with a mean of 49.5 years (SD 12.8 years). There were 165 (78.9\%) with hemophilia A and 39 (18.7\%) with hemophilia B (in five cases hemophilia type was not known). There were 70 (33.5\%) with mild or moderate hemophilia and 132 (63.2\%) with severe hemophilia (in seven cases hemophilia severity was not known). There were 97 (46.4\%) who received the booklet and DVD at baseline (group 1), and 112 (53.6\%) who received the booklet at baseline and the DVD after six-month follow-up (group 2).

The present study sample comprised 78 men who remained in the primary project to 12-month follow-up, so the inclusion and exclusion criteria were as above with retention in the study as an additional inclusion criterion. Ages ranged from 26 to 81 years with a mean of 51.38 years (SD 12.52 years). There were 62 (79.5\%) with hemophilia A and 14 (17.9\%) with hemophilia B (in two cases hemophilia type was not known). There were 27 (34.6\%) with mild or moderate hemophilia and 49 $(62.8 \%)$ with severe hemophilia (in two cases hemophilia severity was not known). There were 43 (55.1\%) who received the booklet and DVD at baseline (group 1), and 35 (44.9\%) who received the booklet at baseline and the DVD after six-month follow-up (group 2).

Baseline descriptive statistics for the initial and present samples are given in Appendix 1. The two samples were very similar demographically and clinically. The present sample had lower baseline contemplation [mean 3.05 (SD 0.65)] than the remainder of the initial study sample [mean 3.25 (SD $0.62), \mathrm{T}_{(193)}=2.11, p=0.036$ ] but did not differ in age, hemophilia type or severity, or any other baseline measures.

\section{Measures}

Pain self-management - motivation and behavior

The Pain Stages of Change Questionnaire (PSOCQ; Kerns et al., 1997) gives scores for four scales. Precontemplation measures motivation to self-manage pain, with higher scores indicating less perceived personal responsibility for pain control and less interest in adopting self-management. Contemplation measures consideration of behavioral changes associated with self-management of pain, and awareness 
of personal responsibility for pain control. Action measures active involvement in learning selfmanagement strategies for pain control. Maintenance measures incorporation of self-management techniques into daily life. The PSOCQ scales have good reliability and validity, with internal reliability ranging from .77 to .88 and test-retest reliability from 0.74 to 0.86 (Kerns \& Rosenberg, 2000; Kerns et al., 1997). However, scores for action and maintenance have been shown to be closely correlated, leading one review to conclude that they "largely assess the same phenomenon" (Dijkstra, 2005, p. 32), so a combined measure computed as the mean of action and maintenance was used for the data analysis.

Pain coping

The Haemophilia Pain Coping Questionnaire (HPCQ) is a 27-item measure of pain coping in hemophilia with three scales: active coping, passive adherence, and negative thoughts. In the present study only the active coping scale was used, which measures active cognitive and behavioral pain coping strategies, with higher scores indicating greater active pain coping. The psychometrics of this scale are good, with internal reliability of 0.80 and test-retest reliability of 0.70 (Elander \& Robinson, 2008).

Pain acceptance

The Chronic Pain Acceptance Questionnaire (CPAQ) is a 20-item scale with two subscales. Activity engagement measures engagement in activities when in pain, and pain willingness measures recognition that avoidance and control are often unworkable ways of living with chronic pain, with higher scores indicating greater acceptance in each case. The two subscale scores can be added together to give a total pain acceptance score. The subscales have good internal reliability; 0.82 for activity engagement and 0.78 for pain willingness (McCracken et al., 2004).

\section{Procedure}

All communication with participants was by post. After completing baseline questionnaire measures, all the participants were sent the information booklet and half, selected randomly, were also sent the DVD. Six months later, participants completed follow-up questionnaire measures and the DVD was then sent to all those who previously received only the booklet. At 12 months, participants again completed follow-up questionnaire measures. The research protocol was approved by the London Metropolitan University Research Ethics Committee (Ref FREC/PMIH01).

\section{Data analysis}

Mean values were substituted for missing values of items in the precontemplation, contemplation, action/maintenance, active coping, activity engagement and pain willingness scales if more than half the items in a scale at any one time point were non-missing, using the same method as previous analyses (Elander et al., 2011; 2013).

The hypotheses were tested using cross-lagged panel analysis, a well-established method for testing causal sequences of change while controlling for the effects of key extraneous variance and ruling out reverse causal effects (Finkel, 1995; Kenny, 1975; 2014; Newsom, 2016). As illustrated in Fig. 2 , cross-lagged analyses test the effect of one factor at time 1 (A1 in Fig. 2) on a second factor at time 2 (B2 in Fig. 2), controlling for the effects of autocorrelations (between the same variable at different 
times) and synchronous correlations (between different variables at the same time). A reverse analysis then tests for any effect of the second factor at time 1 (B1 in Fig. 2) on the first factor at time 2 ( $A 2$ in Fig 2).

Figure. 2. The cross-lagged panel design. Note: $A$ and $B$ represent separate factors or processes; 1 and 2 represent time points; lines a represent autocorrelations; lines b represent synchronous correlations; lines $\mathrm{c}$ represent cross-lagged correlations.

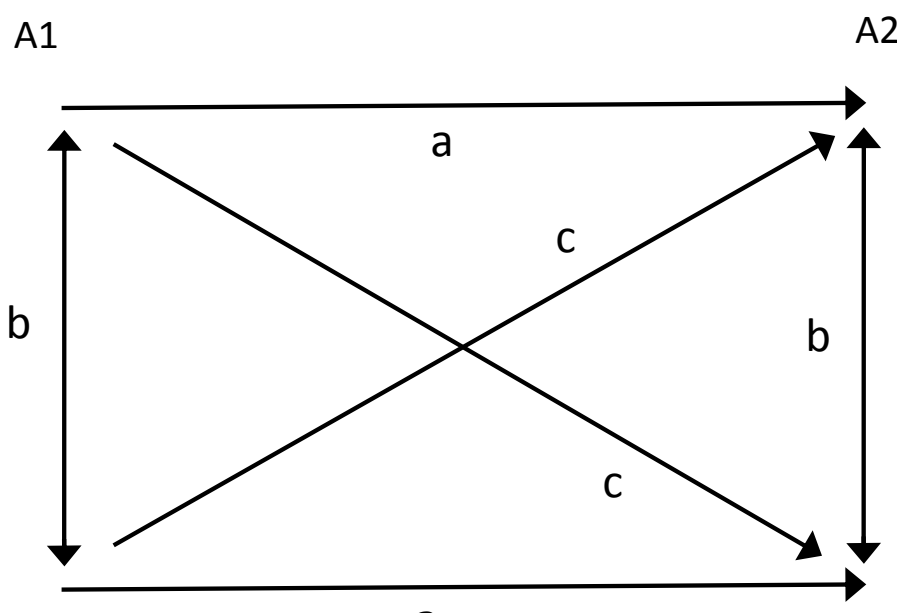

a

B1

B2

Cross-lagged panel analyses following a standard procedure have frequently been used to test specific causal change processes during treatments for chronic pain (Burns et al., 1998, 2003a, 2003b, 2005; Campbell et al., 2012; Evon \& Burns, 2004; Glen \& Burns, 2003). The present analyses followed the same standard procedure:

1. Differences between mean scores at each time point were examined using repeated measures analysis of variance.

2. 'Early' (baseline-to-6-month) and 'later' (6-to-12-month) residualized change scores were computed for each measure by regressing baseline scores onto 6-month scores and 6-month scores onto 12month scores. Variance attributable to baseline values is removed from residualized change scores, so they measure change independent of baseline values (Llabre et al., 1991).

3. Cross-lagged correlations that corresponded to the hypotheses were examined.

4. For cross-lagged correlations that were significant, two-step multiple regression analyses were used to test whether the cross-lagged effect was independent of the autocorrelation and synchronous correlation.

5. If the cross-lagged regression analysis showed a significant independent effect, the reverse analysis was conducted to test for any reverse effect.

For hypothesis 1 , the effects of early changes in precontemplation and contemplation on later changes in active coping and action/maintenance were tested.

For hypothesis 2 , the effect of early change in activity engagement on later change in pain willingness was tested. 
For hypothesis 3, the effect of early change in pain willingness on later change in activity engagement was tested.

Five covariates were also included in all the regression analyses in addition to the autocorrelate and synchronous correlate: age, hemophilia severity, 'group' (whether participants received the DVD at baseline or after 6-month follow-up), and the baseline measures of the factors being tested as cause and effect. Predictor variables were added to the models in two steps: 1) the covariates plus the autocorrelate and synchronous correlate; 2 ) the hypothesized causal variable. We also conducted subgroup analyses to explore potentially different change processes among each group, following the same process of correlations followed by regression as in the main analyses, with the same covariates in each case.

To supplement the regression analyses, we explored patterns of change using latent change analyses (Preacher et al., 2008) and assessed causal change processes by testing structural equation models (Kline, 2011). These all used unstandardized scores at each time point rather than residualized change scores, consistent with best practice for structural equation modeling (Kline, 2011, p. 459). However, both latent change analysis and structural equation modeling require at least 200 participants (Barrett, 2007; Preacher et al., 2008), so these analyses should be interpreted with caution and are presented in summary form with more information in Appendix 2.

\section{Results}

Among the 78 participants in the present sample, the numbers of missing values substitutions for each scale at baseline, 6-month and 12-month follow up respectively were: precontemplation 3, 1, 3; contemplation 4, 1, 2; action/maintenance 5, 4, 7; active coping 1, 2, 2; activity engagement 0, 4, 4; pain willingness 1, 4, 4. Alpha internal reliability coefficients for the scales at baseline, 6-month and 12 month follow-up respectively were: precontemplation $0.78,0.80,0.76$; contemplation $0.84,0.84,0.82$; action/maintenance $0.87,0.87,0.88$; active coping $0.82,0.83,0.84$; activity engagement $0.80,0.82$, 0.85 ; pain willingness $0.76,0.81,0.81$.

Table 1 shows mean values and tests of early (baseline vs. six months) and later (six vs. 12 months) changes. From baseline to six months, active coping increased significantly, but there were no significant changes from six to 12 months. For pain acceptance total there was a marginally significant increase from baseline to six months $\left[F_{(1,76)}=2.77, p=0.100\right]$, and for pain willingness there was a marginally significant increase from baseline to 12 months $\left[F_{(1,76)}=3.80, p=0.055\right]$. There were no significant effects of group or time $x$ group.

The correlations among change scores are shown in table 2. In both early and later periods there were significant positive synchronous correlations between changes in contemplation and action/maintenance, and between changes in action/maintenance and active coping. In both periods there were also significant negative synchronous correlations between changes in contemplation and pain willingness. In the later period but not the first, there were significant positive synchronous correlations between changes in action/maintenance and activity engagement, and between changes in active coping and activity engagement. In the later period there was also a significant negative synchronous correlation between changes in contemplation and acceptance total. 
Table 1. Mean values and tests of differences between time points

\begin{tabular}{|c|c|c|c|c|c|c|}
\hline & $\begin{array}{l}\text { Baseline mean } \\
\text { (SD [95\% Cls]) }\end{array}$ & F ratio $^{a}$ & $\begin{array}{l}\text { Six month mean } \\
\text { (SD }[95 \% \mathrm{Cls}])\end{array}$ & F ratio $^{b}$ & $\begin{array}{l}12 \text { month mean } \\
\text { (SD }[95 \% \mathrm{Cls}])\end{array}$ & F ratio $^{c}$ \\
\hline Precontemplation & $2.85(0.71[2.69,3.02])$ & $F=1.37$ & $2.76(0.72[2.59,2.93])$ & $F=1.50$ & $2.85(0.67[2.69,3.00])$ & $F=0.94$ \\
\hline Contemplation & $3.08(0.63[2.93,3.23])$ & $F=0.11$ & $3.06(0.62[2.92,3.20])$ & $F=1.06$ & $3.01(0.61[2.87,3.15])$ & $F=0.89$ \\
\hline Action/maintenance & $3.13(0.60[2.99,3.27])$ & $F=0.001$ & $3.14(0.58[3.00,3.27])$ & $F=1.26$ & $3.08(0.61[2.94,3.22])$ & $F=0.66$ \\
\hline Active coping & $2.28(1.12[2.02,2.54])$ & $\mathrm{F}=19.53 * * *$ & $2.72(1.10[2.46,2.97])$ & $F=0.24$ & $2.68(1.08[2.43,2.93])$ & $\mathrm{F}=12.72 * * *$ \\
\hline Activity engagement & $40.23(10.75[37.81,42.66])$ & $F=1.37$ & 41.51 (10.04 [39.24, 43.77]) & $F=1.83$ & $40.23(10.67[37.83,42.64])$ & $F=1.10$ \\
\hline Pain willingness & $25.37(9.08[23.33,27.42])$ & $F=1.36$ & 26.21 (9.31 [24.11, 28.31]) & $F=0.71$ & $26.91(8.93[24.90,28.92])$ & $F=1.98$ \\
\hline Acceptance total & $65.61(16.51[61.88,69.33])$ & $F=2.77$ & $67.72(14.75[64.39,71.04])$ & $F=0.23$ & $67.14(15.54)[63.64,70.65])$ & $F=1.45$ \\
\hline
\end{tabular}

Notes:

a. F ratios comparing baseline and six-month values

b. F ratios comparing six-month and 12-month values

c. F ratios for overall comparison between baseline, six-month and 12 - month values

$\mathrm{SD}=$ standard deviation; $\mathrm{Cls}=$ confidence intervals

* $p<0.05$; * $p<0.01$; ** $p<0.001$ 
Table 2. Correlations among residualized change scores

\begin{tabular}{|c|c|c|c|c|c|c|c|c|c|c|}
\hline 1. Precontemplation early change & 1.00 & & & & & & & & & \\
\hline 2. Precontemplation later change & $-0.24^{*}$ & 1.00 & & & & & & & & \\
\hline 3. Contemplation early change & 0.12 & -0.23 & 1.00 & & & & & & & \\
\hline 4. Contemplation later change & -0.02 & 0.07 & -0.10 & 1.00 & & & & & & \\
\hline 5. Action/maintenance early change & -0.04 & 0.02 & $0.40 * *$ & 0.11 & 1.00 & & & & & \\
\hline 6. Action/maintenance later change & -0.18 & 0.08 & -0.19 & $0.24 *$ & -0.11 & 1.00 & & & & \\
\hline 7. Active coping early change & -0.08 & 0.08 & -0.05 & 0.06 & $0.25 *$ & -0.01 & 1.0 & & & \\
\hline 8. Active coping later change & $-0.32 * *$ & -0.02 & 0.07 & 0.04 & 0.12 & $0.33 * *$ & $-0.32 * *$ & 1.0 & & \\
\hline 9. Activity engagement early change & -0.08 & -0.16 & 0.17 & -0.02 & 0.14 & -0.08 & 0.13 & -0.15 & 1.0 & \\
\hline 10. Activity engagement later change & $-0.31 * *$ & 0.05 & 0.00 & -0.12 & -0.01 & $0.24^{*}$ & 0.12 & $0.23^{*}$ & $-0.38 * *$ & 1.0 \\
\hline 11. Pain willingness early change & -0.23 & -0.05 & $-0.34 * *$ & -0.15 & -0.19 & 0.02 & 0.07 & 0.02 & -0.10 & 0.17 \\
\hline 12. Pain willingness later change & -0.03 & -0.20 & 0.21 & $-0.28^{*}$ & -0.11 & -0.02 & 0.02 & -0.11 & $0.23^{*}$ & -0.03 \\
\hline 13. Acceptance total early change & -0.19 & -0.13 & -0.11 & -0.10 & -0.05 & -0.07 & 0.14 & -0.14 & $0.73 * *$ & $-0.24 *$ \\
\hline \multirow[t]{2}{*}{ 14. Acceptance total later change } & -0.20 & -0.08 & 0.20 & $-0.28 *$ & -0.09 & 0.16 & 0.10 & 0.09 & -0.18 & $0.74 * *$ \\
\hline & 1 & 2 & 3 & 4 & 5 & 6 & 7 & 8 & 9 & 10 \\
\hline
\end{tabular}

\section{Table 2 continued}

\begin{tabular}{llll}
\hline 11. Pain willingness early change & 1.0 & & \\
12. Pain willingness later change & $-0.27^{*}$ & 1.0 & \\
13. Acceptance total early change & $0.58^{* *}$ & -0.01 & 1.0 \\
14. Acceptance total later change & -0.15 & $0.63^{* *}$ & $-0.27^{*}$ \\
\hline & 11 & 12 & 13 \\
\hline
\end{tabular}

$* p<0.05 ; * * p<0.01$ 
The synchronous correlations seemed to show that changes in pain willingness were related negatively to changes in contemplation, whereas changes in activity engagement were related positively to changes in active coping and action/maintenance. The synchronous correlations between changes in activity engagement and pain willingness were non-significant and close to zero $(-0.10$ and -0.03$)$, so the two components of pain acceptance changed independently of one another.

\section{Hypothesis 1}

The predicted correlation between early change in precontemplation and later change in active coping was significant $(r=-0.32, p<0.01)$. Also, although not specifically predicted, the correlation between early change in precontemplation and later change in activity engagement was significant $(r=-$ $0.31, p<0.01$ ), so that is potentially another example of motivational change influencing behavioral change. However the predicted correlation between early change in precontemplation and later change in action/maintenance was not significant.

Regression analysis showed a significant effect of early change in precontemplation on later change in active coping, independently of the covariates, early change in active coping (the autocorrelate) and later change in precontemplation (the synchronous correlate). In the reverse analysis, there was no significant effect of early change in active coping on later change in precontemplation (Table 3). This supports hypothesis 1 and illustrates a motivational-behavioral change process in which changes in motivation led to subsequent changes in coping, consistent with Jensen et al.'s (2003a) model.

Regression analyses also showed a significant independent effect of early change in precontemplation on later change in activity engagement, with no significant reverse effect of early change in activity engagement on later change in precontemplation (Table 4). This again seems to illustrate a motivational-behavioral change process in which motivational change led to subsequent behavioral change.

We also tested those effects among each group. Among group 1, who received the DVD at baseline, the correlation between early change in precontemplation and later change in active coping was $-0.39(p=0.013)$, and that between early change in precontemplation and later change in activity engagement was $-0.075(p=0.64)$. Regression analysis showed a significant independent effect of early change in precontemplation on active coping $\left(\mathrm{B}=-0.480[95 \% \mathrm{Cls}-0.804,-0.156]\right.$, step $2 \Delta \mathrm{R}^{2}=0.179, p=$ $0.005)$, and no significant reverse effect of early change in active coping on later change in precontemplation ( $\mathrm{B}=0.138$ [95\% Cls $-0.300,0.576]$, step $2 \Delta \mathrm{R}^{2}=0.009, p=0.525$ ).

Among group 2, who received the DVD at six months, the correlation between early change in precontemplation and later change in active coping was $-0.277(p=0.138)$, and that between early change in precontemplation and later change in activity engagement was $-0.578(p=0.001)$. Regression analysis showed a significant independent effect of early change in precontemplation on activity engagement ( $B=-0.375$ [95\% Cls $-0.608,-0.141$ ], step $2 \Delta R^{2}=0.263, p=0.003$ ), but also a marginally significant reverse effect of early change in activity engagement on later change in precontemplation ( $B$ $=-0.298$ [95\% Cls $-0.595,0.000]$, step $2 \Delta R^{2}=0.113, p=0.050$ ).

It therefore appeared that reductions in precontemplation had more effect on active coping among one group and more effect on activity engagement among the other. However, the subgroup regression analyses should be interpreted with caution because of the smaller sample size. One rule of 
thumb for multiple regression is that $\mathrm{n}$ should be at least 50 plus the number of predictor variables (Tabachnick \& Fidell, 1996, p. 132).

Table 3. Regression analysis testing early change in precontemplation as a predictor of later change in active coping

\begin{tabular}{|c|c|c|c|c|c|}
\hline Block and predictor variable & $\mathrm{B}[95 \% \mathrm{Cls}]$ & SE B & $\begin{array}{c}\text { Step } \\
\mathrm{R}^{2} \\
\end{array}$ & $\begin{array}{c}\text { Step } \\
{ }^{2} \\
\Delta R^{2}\end{array}$ & $\begin{array}{c}P \\
\text { Step } \Delta R\end{array}$ \\
\hline \multicolumn{6}{|c|}{ Main analysis with later change in active coping as dependent variable } \\
\hline \multicolumn{6}{|c|}{ Step 1} \\
\hline Age & $-0.027[-0.048,-0.006]$ & 0.010 & & & \\
\hline Severity & $-0.201[-0.516,0.113]$ & 0.157 & & & \\
\hline Group $^{\mathrm{a}}$ & $0.042[-0.438,0.522]$ & 0.240 & & & \\
\hline Baseline precontemplation & $0.029[-0.313,0.372]$ & 0.171 & & & \\
\hline Baseline active coping & $0.112[-0.097,0.321]$ & 0.105 & & & \\
\hline Early change in active coping ${ }^{\mathrm{b}}$ & $-0.384[-0.639,-0.130]$ & 0.127 & & & \\
\hline Later change in precontemplation ${ }^{c}$ & $-0.001[-0.250,0.247]$ & 0.124 & 0.220 & 0.220 & 0.028 \\
\hline \multicolumn{6}{|l|}{ Step 2} \\
\hline Early change in precontemplation & $-0.316[-0.547,-0.084]$ & 0.116 & 0.306 & 0.086 & 0.008 \\
\hline \multicolumn{6}{|c|}{ Reverse analysis with later change in precontemplation as dependent variable } \\
\hline \multicolumn{6}{|c|}{ Step 1} \\
\hline Age & $-0.002[-0.023,0.019]$ & 0.011 & & & \\
\hline Severity & $-0.008[-0.327,0.311]$ & 0.160 & & & \\
\hline Group $^{\mathrm{a}}$ & $-0.033[-0.513,0.448]$ & 0.240 & & & \\
\hline Baseline precontemplation & $0.434[0.106,0.763]$ & 0.164 & & & \\
\hline Baseline active coping & $-0.049[-0.262,0.164]$ & 0.106 & & & \\
\hline Early change in precontemplation ${ }^{b}$ & $-0.262[-0.508,-0.016]$ & 0.123 & & & \\
\hline Later change in active coping ${ }^{c}$ & $-0.120[-0.369,0.129]$ & 0.124 & 0.163 & 0.163 & 0.126 \\
\hline \multicolumn{6}{|l|}{ Step 2} \\
\hline Early change in active coping & $0.081[-0.196,0.359]$ & 0.139 & 0.168 & 0.005 & 0.560 \\
\hline
\end{tabular}

Notes:

Cls=confidence intervals

a. Coded 1=received DVD at baseline (group 1), 2=received DVD at six months (group 2)

b. Autocorrelate

c. Synchronous correlate 
Table 4. Regression analyses testing early change in precontemplation as a predictor of later change in activity engagement

\begin{tabular}{|c|c|c|c|c|c|}
\hline Block and predictor variable & $\mathrm{B}[95 \% \mathrm{Cls}]$ & SE B & $\begin{array}{c}\text { Step } \\
\mathrm{R}^{2} \\
\end{array}$ & $\begin{array}{c}\text { Step } \\
{ }^{2} \\
\Delta R^{2}\end{array}$ & $\begin{array}{c}P \\
\text { Step } \Delta R\end{array}$ \\
\hline \multicolumn{6}{|c|}{ Main analysis with later change in activity engagement as dependent variable } \\
\hline \multicolumn{6}{|c|}{ Step 1} \\
\hline Age & $-0.015[-0.031,0.000]$ & 0.008 & & & \\
\hline Severity & $-0.055[-0.295,0.185]$ & 0.120 & & & \\
\hline Group $^{\mathrm{a}}$ & $-0.155[-0.526,0.216]$ & 0.186 & & & \\
\hline Baseline precontemplation & $0.224[-0.058,0.506]$ & 0.141 & & & \\
\hline Baseline activity engagement & $0.027[0.009,0.044]$ & 0.009 & & & \\
\hline Early change in activity engagement ${ }^{b}$ & $-0.220[-0.426,-0.013]$ & 0.103 & & & \\
\hline Later change in precontemplation ${ }^{c}$ & $-0.081[-0.279,0.118]$ & 0.099 & 0.256 & 0.256 & 0.006 \\
\hline \multicolumn{6}{|l|}{ Step 2} \\
\hline Early change in precontemplation & $-0.257[-0.442,-0.071]$ & 0.093 & 0.337 & 0.081 & 0.007 \\
\hline \multicolumn{6}{|c|}{ Reverse analysis with later change in precontemplation as dependent variable } \\
\hline \multicolumn{6}{|c|}{ Step 1} \\
\hline Age & $0.000[-0.021,0.020]$ & 0.010 & & & \\
\hline Severity & $0.031[-0.266,0.327]$ & 0.148 & & & \\
\hline Group $^{\mathrm{a}}$ & $-0.038[-0.499,0.423]$ & 0.231 & & & \\
\hline Baseline precontemplation & $0.461[0.123,0.799]$ & 0.169 & & & \\
\hline Baseline activity engagement & $0.006[-0.018,0.029]$ & 0.012 & & & \\
\hline Early change in precontemplation ${ }^{b}$ & $-0.269[-0.506,-0.031]$ & 0.119 & & & \\
\hline Later change in activity engagement ${ }^{c}$ & $-0.159[-0.465,0.147]$ & 0.153 & 0.158 & 0.158 & 0.120 \\
\hline \multicolumn{6}{|l|}{ Step 2} \\
\hline Early change in activity engagement & $-0.251[-0.507,0.004]$ & 0.128 & 0.207 & 0.049 & 0.054 \\
\hline
\end{tabular}

Notes to table 4:

$\mathrm{Cls}=$ confidence intervals

a. Coded 1=received DVD at baseline (group 1), 2=received DVD at six months (group 2)

b. Autocorrelate

c. Synchronous correlate

\section{Hypotheses 2 and 3}

The correlation predicted by hypothesis 2 between early change in activity engagement and later change in pain willingness was significant $(r=0.23, p=0.04)$, but that predicted by hypothesis 3 between early change in pain willingness and later change in activity engagement was not $(r=0.17, p=$ 0.14). Regression analysis showed a significant independent effect of early change in activity engagement on later change in pain willingness (Table 5). This supports hypothesis 2 and illustrates a behavioral-motivational change process in which changes in activity engagement led to subsequent changes in pain willingness, consistent with the behavioral model of pain acceptance. However, in the reverse analysis, which is also a test of hypothesis 3 , there was also a just significant effect of early change in pain willingness on later change in activity engagement. 
The subgroup analyses showed that among group 1, the correlation between early change in activity engagement and later change in pain willingness was $0.201(p=0.196)$, and that between early change in pain willingness and later change in activity engagement was $0.288(p=0.061)$. Among group 2 , the correlation between early change in activity engagement and later change in pain willingness was $0.243(p=0.160)$ and that between early change in pain willingness and later change in activity engagement was $0.055(p=0.755)$.

Table 5. Regression analysis testing early change in activity engagement as a predictor of later change in pain willingness and early change in pain willingness as a predictor of later change in activity engagement

\begin{tabular}{|c|c|c|c|c|c|}
\hline & B [95\% Cls] & SE B & $R^{2}$ & $\begin{array}{c}\text { Step } \\
{ }^{2} \\
\Delta R^{2}\end{array}$ & $\begin{array}{c}P \\
\text { Step } \Delta R^{2}\end{array}$ \\
\hline \multicolumn{6}{|c|}{ Hypothesis 2: Later change in pain willingness as dependent variable } \\
\hline \multicolumn{6}{|c|}{ Step 1} \\
\hline Age & $0.013[[-0.006,0.032]$ & 0.010 & & & \\
\hline Severity & $0.021[-0.257,0.300]$ & 0.140 & & & \\
\hline Group $^{a}$ & $0.082[-0.340,0.504]$ & 0.211 & & & \\
\hline Baseline activity engagement & $-0.009[-0.031,0.013$ & 0.011 & & & \\
\hline Baseline pain willingness & $0.036[0.011,0.061]$ & 0.013 & & & \\
\hline Early change in pain willingness ${ }^{b}$ & $-0.302[-0.514,-0.090]$ & 0.106 & & & \\
\hline Later change in activity engagement ${ }^{c}$ & $0.206[-0.037,0.450]$ & 0.122 & 0.220 & 0.220 & 0.015 \\
\hline \multicolumn{6}{|l|}{ Step 2} \\
\hline Early change in activity engagement & $0.275[0.062,0.487]$ & 0.106 & 0.290 & 0.071 & 0.012 \\
\hline \multicolumn{6}{|c|}{ Hypothesis 3: Reverse analysis with later change in activity engagement as dependent variable } \\
\hline \multicolumn{6}{|c|}{ Step 1} \\
\hline Age & $-0.019[-0.037,-0.002]$ & 0.009 & & & \\
\hline Severity & $-0.098[-0.351,0.156]$ & 0.127 & & & \\
\hline Group $^{\mathrm{a}}$ & $0.172[-0.558,0.214]$ & 0.194 & & & \\
\hline Baseline activity engagement & $0.028[0.009,0.047]$ & 0.010 & & & \\
\hline Baseline pain willingness & $-0.017[-0.041,0.007]$ & 0.012 & & & \\
\hline Early change in activity engagement ${ }^{\mathrm{b}}$ & $-0.361[-0.552,-0.169]$ & 0.096 & & & \\
\hline Later change in pain willingness ${ }^{c}$ & $0.216[0.005,0.428]$ & 0.106 & 0.319 & 0.319 & $<0.001$ \\
\hline \multicolumn{6}{|l|}{ Step 2} \\
\hline Early change in pain willingness & $0.197[0.003,0.392]$ & 0.097 & 0.358 & 0.039 & 0.046 \\
\hline
\end{tabular}

Notes to table 5:

$\mathrm{Cls}=$ confidence intervals

a. Coded 1=received DVD at baseline (group 1), 2=received DVD at six months (group 2)

b. Autocorrelate

c. Synchronous correlate 


\section{Supplementary analyses}

The latent change analyses showed that active coping had a positive slope indicating significant change over time, consistent with the tests of differences given in Table 1. A series of structural equation models were then tested. For hypothesis 1 , we began with a model in which early changes in precontemplation and contemplation predicted later changes in active coping, action/maintenance and activity engagement, then successively removed variables in a series of simpler models that were considered further only if they did not contain variables with negative error variances, which indicate mis-specification ('Heywood Cases'; Kline, 2011). The best fitting model was one with significant pathways from early changes in both precontemplation and contemplation to later change in active coping.

For hypotheses 2 and 3, we tested one model for each hypothesis. The model testing hypothesis 2 was slightly better fitting, but the two models were almost equally well-fitting and the hypothesized pathways were not significant in either model. More information about the latent change analyses and structural equation modeling are given in Appendix 2.

\section{Discussion}

Hypothesis 1 was supported, for early change in motivation to self-manage pain influenced later change in active coping, in both the regression analysis and the best fitting structural equation model. This is the first evidence to our knowledge about the specific sequence of motivational-behavioral changes predicted by the motivational model of pain self-management. It suggests that interventions should focus on increasing motivation to self-manage before trying to increase active pain coping.

Hypothesis 2 was supported more strongly than hypothesis 3, for early change in activity engagement was significantly correlated with later change in pain willingness, whereas early change in pain willingness was not significantly correlated with later change in activity engagement. In the regression analysis early change in activity engagement influenced later change in pain willingness more strongly than early change in pain willingness influenced later change in activity engagement.

This is again the first evidence to our knowledge about how changes in activity engagement and pain willingness influence one another, and the results supported the behavioral model of pain acceptance more strongly than the motivational model. They suggest that changes in pain acceptance are largely driven by changes in behavior, so efforts to improve pain acceptance should focus first on changing behavioral aspects of acceptance.

However, in spite of the non-significant correlation between early change in pain willingness and later change in activity engagement, the multiple regression analyses showed a weak but still just significant effect of early change in pain willingness on later change in activity engagement. This suggests that not all changes in pain acceptance follow the sequence of behavioral change leading to motivation or attitude change, so we should continue to allow for cases where changes in pain willingness lead to changes in activity engagement.

The findings supported a motivational model of pain self-management and a behavioral model of pain acceptance, which seems to suggest that self-management and acceptance involve very different change processes. However, in the regression analyses, increased motivation to self-manage (reduced precontemplation) influenced later increases in activity engagement, the behavioral component of pain acceptance, as well as active coping. This may indicate that precontemplation involves resistance to 
taking responsibility for self-management in a broad sense, not just by coping with pain, so it may be worth reducing precontemplation before trying to increase pain acceptance as well as before trying to increase pain coping.

Coping and acceptance are sometimes presented as contrasting approaches. Coping-based interventions are often based on cognitive-behavioral therapy, whereas acceptance-based interventions are usually based on acceptance and commitment therapy, and coping usually involves conscious, intentional processes, whereas acceptance often involves automatic, non-intentional processes (McCracken \& Eccleston, 2003, 2006; McCracken et al., 2007).

However, improving pain acceptance could help people develop more limited, realistic coping that does not lead to feelings of failure and defeat, and more realistic coping could help people develop greater pain acceptance. In one study both acceptance-based and cognitive-behavioral interventions improved both pain acceptance and beliefs about control over pain (Wetherell et al., 2011). In another, pain acceptance mediated the effects of CBT-based treatment for chronic pain (Åkerblom et al., 2015). In the present study, increases in active coping and activity engagement were positively correlated during the later period.

Combining or linking coping-based and acceptance-based approaches to chronic pain is also worthwhile because pain acceptance is increasingly applied in chronic conditions where coping and selfmanagement are important, like hemophilia (Elander, 2014), and to specific aspects of self-management like self-medication (Elander et al., 2014). Self-management of chronic illness can include coping, but also self-monitoring, self-care and emotional self-regulation (Barlow et al., 2002). Pain acceptance may be a specific form of behavioral and emotional self-regulation, and a better understanding of how pain acceptance is related to other aspects of self-management could help to guide the adaptation of acceptance-based interventions for different chronic conditions. However, people with hemophilia must differentiate chronic pain associated with joint damage caused by past bleeds from acute pain caused by active bleeding, which should be treated promptly with clotting factor concentrates (RodriguezMerchan, 2012). Acceptance-based interventions must avoid compromising that aspect of selfmanagement for people with hemophilia.

Figure 3. A combined model of changes in pain self-management and acceptance

Motivation

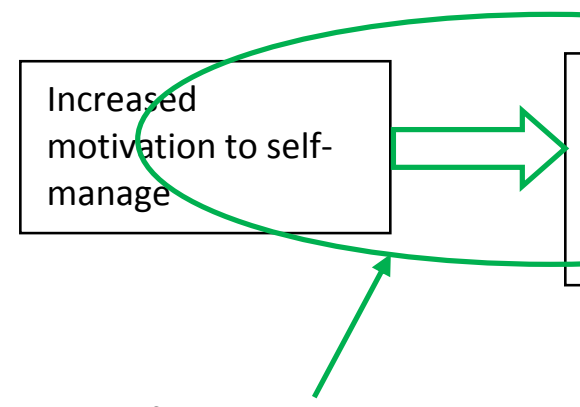

Self-management phase

in which motivational

changes lead to

behavioral changes
Behavior

Deeper attitudes and values
Acceptance phase in which behavioral changes lead to changes in acceptance-related attitudes 
Because motivation to self-manage seems to be a precondition for improving both coping and acceptance, motivational interventions could be used as a prelude to coping-based and acceptancebased interventions. In a combined model of changes in pain self-management and acceptance, improved motivation to self-manage pain leads to increases in active coping and/or activity engagement, which then leads to increases in pain willingness (Fig. 3).

This model involves a motivational change process in the first phase and a behavioral change process in the second, so it is consistent with both the motivational model of pain self-management and the behavioral model of pain acceptance, and it treats both coping and acceptance as aspects of behavioral self-management of chronic pain. It predicts that changes in pain acceptance follow changes in other aspects of self-management, and that pain willingness takes longer and is more difficult to change than activity engagement.

The findings also suggest that activity engagement is a behavioral construct whereas pain willingness is a motivation or attitude that is influenced by prior behavioral changes. Activity engagement and pain willingness changed independently of one another and had different relationships with other factors, and all the significant correlations involving changes in pain acceptance involved CPAQ subscales rather than the pain acceptance total score, which supports the validity of the CPAQ subscales as distinct aspects of pain acceptance. More research is needed on the meaning of pain willingness, however, for it appears not to be a traditional motivational factor, but rather a deeper attitude reflecting more advanced adjustment to chronic pain.

Several methodological points should be borne in mind alongside the findings. The participants all had chronic joint pain secondary to hemophilia, so one might question the extent to which the findings would generalize to other chronic pain populations. However, hemophilia is increasingly recognized as a chronic pain condition (Humphries \& Kessler, 2015, 2016), and research on pain selfmanagement, coping and acceptance shows that people with hemophilia respond to chronic pain in very similar ways to those with other chronic pain conditions (Elander, 2014).

The present sample was a subset of a larger initial sample, and residualized change scores are sample-specific, so a person's change score would be different in a different sample. However, the two samples were very similar, with no differences in key variables, so the present sample should be representative of the target population for interventions to improve self-management of chronic joint pain among people with hemophilia.

The sample size was similar to previous cross-lagged analyses of change processes in chronic pain (Burns et al., 1998, 2003a, 2003b, 2005; Campbell et al., 2012; Evon \& Burns, 2004; Glen \& Burns, 2003), and was large enough for the main regression analyses, but the structural equation modeling was underpowered. One guide suggested that, "with $N<100$, almost any type of SEM may be untenable unless a very simple model is analyzed" (Kline, 2011, p. 16). We kept the models as simple as possible but still encountered problems with model specification. The SEM analyses offer an alternative approach to the regression analyses, and are based on static scores at each time point rather than residualized change scores. They produced findings that were consistent with the regression analyses, but they should be regarded primarily as illustrative, whereas the main cross-lagged regression analyses represent planned tests of specific causal processes, using an established method employed in previous comparable analyses. 
More sophisticated treatments for missing values are available, such as multiple imputation (Royston, 2004), but for the sake of consistency we adopted the same method used in previous analyses from the same project (Elander et al., 2011; 2013). In fact, only 52 out of 1,404 scale scores involved missing values substitutions (1,404 $=6$ scales $\times 3$ time points $\times 78$ participants).

The participants all received materials by post, with no personal contact or interaction as part of the study, whereas other studies of change processes typically focused on more intensive treatment programs. As discussed above, however, these findings could inform the use of low-intensity interventions using materials like these as a preliminary to more intensive treatment interventions.

The six-month periods were chosen to give time for participants' motivation and behavior to change through reflection, self-monitoring and re-evaluation, and to ensure that changes were sustained long enough to make a difference in real life. However, this means that changes over shorter periods were not captured in the data, and we do not have information about outcomes beyond the 12month follow-up.

The main analyses combined groups who received the DVD at different times, and in the subgroup analyses, reduced precontemplation influenced active coping more among one group and activity engagement more among the other. This is quite challenging to interpret, but the subgroup analyses should be treated with caution because of the smaller samples, and in the main analyses there were no group effects.

The regression analyses controlled for age, hemophilia severity, group, and baseline levels of motivation, coping and acceptance, but other factors could potentially influence change processes, like previous treatments for joint damage, or how participants used the materials they were sent. Future research might examine changes in coping and acceptance as a function of other factors like those, perhaps in the context of a more intensive self-management intervention.

To conclude, the findings supported the motivational model of pain self-management by demonstrating a motivational-behavioral change sequence, as increased motivation to self-manage influenced later increases in active coping. They also supported the behavioral model of pain acceptance, as increased activity engagement influenced later increases in pain willingness. These findings provide insights into change processes that can help us develop more integrated models of change, which can guide combinations of interventions based on theories of motivation, coping and acceptance in chronic pain.

\section{Acknowledgements}

We are grateful to all the participants in the study, to Tom Bradley and the staff of the Haemophilia Society for undertaking the study mailings, and to the journal reviewers and section editor for their helpful comments on an earlier draft.

\section{Author contributions}

James Elander conceived, designed and conducted the main data analyses and drafted the manuscript. Cassandra Richardson contributed to the conception, data analysis and manuscript drafting. John Morris and Georgina Robinson contributed to the overall conception, design, data collection and manuscript drafting. Malcolm Schofield conducted the latent change analyses and structural equation model testing. All the authors discussed the results and commented on the manuscript. 


\section{References}

Åkerblom, S., Perrin, S., Fischer, M. R., \& McCracken, L. M. (2015). The mediating role of acceptance in multidisciplinary Cognitive-Behavioral Therapy for chronic pain. The Journal of Pain, 16, 606615.

Barlow, J., Wright, C., Sheasby, J., Turner, A., \& Hainsworth, J. (2002). Self-management approaches for people with chronic conditions: a review. Patient Education and Counseling, 48, 177-187.

Barrett, P. (2007). Structural equation modelling: Adjudging model fit. Personality and Individual Differences, 42, 815-824.

Burns, J.W., Johnson, B.J., Mahoney, N., Devine, J., \& Pawl, R. (1998). Cognitive and physical capacity process variables predict long-term outcome after treatment for chronic pain. Journal of Consulting and Clinical Psychology, 66, 434-439.

Burns, J.W., Glenn, B., Bruehl, S., Harden, R.N., \& Lofland, K. (2003a). Cognitive factors influence outcome following multidisciplinary chronic pain treatment: a replication and extension of a cross-lagged panel analysis. Behaviour Research and Therapy, 41, 1163-1182.

DOI:10.1016/S0005-7967(03)00029-9

Burns, J.W., Kubilis, A., Bruehl, S., Harden, R.N., \& Lofland, K. (2003b). Do changes in cognitive factors influence outcome following multidisciplinary treatment for chronic pain? A cross-lagged panel analysis. Journal of Consulting and Clinical Psychology, 71, 81-91. http://dx.doi.org/10.1037/0022-006X.71.1.81

Burns, J.W., Glenn, B., Lofland, K., Bruehl, S., \& Harden, R.N. (2005). Stages of change in readiness to adopt a self-management approach to chronic pain: the moderating role of early-treatment stage progression in predicting outcome. Pain, 115, 322-331.

Campbell, C.M., McCauley, L., Bounds, S.C., Mathur, V.A., Conn, L., Simango, M., Edwards, R.R., \& Fontaine, K.R. (2012). Changes in pain catastrophizing predict later changes in fibromyalgia clinical and experimental pain report: cross-lagged panel analyses of dispositional and situational catastrophizing. Arthritis Research and Therapy, 14(5), R231. DOI: 10.1186/ar4073

Dijkstra, A. (2005). The validity of the stages of change model in the adoption of the self-management approach in chronic pain. Clinical Journal of Pain, 21, 27-37.

Elander, J. (2014). A review of evidence about behavioural and psychological aspects of chronic joint pain among people with haemophilia. Haemophilia, 20, 168-175. DOI: 10.1111/hae.12291

Elander, J., Duarte, J., Maratos, F.A., \& Gilbert, P. (2014). Predictors of painkiller dependence among people with pain in the general population. Pain Medicine, 15 (4), 613-624. DOI: 10.1111/pme.12263

Elander, J. \& Robinson, G. (2008). A brief haemophilia pain coping questionnaire (HPCQ). Haemophilia, 14, 1039-1048. DOI: 10.1111/j.1365-2516.2008.01822.x

Elander, J., Robinson, G., \& Morris, J. (2011). Randomized trial of a DVD intervention to improve readiness to self-manage joint pain. Pain 152, 2333-2341. DOI:10.1016/j.pain.2011.06.026

Elander, J., Morris, J. \& Robinson, G. (2013). Pain coping and acceptance as longitudinal predictors of health-related quality of life among people with hemophilia-related chronic joint pain. European Journal of Pain, 17, 929-938. DOI:10.1002/j.1532-2149.2012.00258.x

Evon, D.M. \& Burns, J.W. (2004). Process and outcome in cardiac rehabilitiation: an examination of cross-lagged effects. Journal of Consulting and Clinical Psychology, 72, 605-616. 
Finkel, S.E. (1995). Causal analysis with panel data. Thousand Oaks, CA: Sage Publications.

Glenn, B. \& Burns, J.W. (2003). Pain self-management in the process and outcome of multidisciplinary treatment of chronic pain: Evaluation of a stage of change model. Journal of Behavioral Medicine. 26, 417-433. DOI: 10.1023/A:1025720017595

Hayes, S.C. (2004). Acceptance and commitment therapy, relational frame theory, and the third wave of behavioral and cognitive therapies. Behavior Therapy, 35, 639-665. DOI: 10.1016/S00057894(04)80013-3

Hayes, S.C., Luoma, J. B., Bond, F. W., Masuda, A., \& Lillis, J. (2006). Acceptance and commitment therapy: model, processes and outcomes. Behaviour Research and Therapy, 44, 1-25. DOI: 10.1016/j.brat.2005.06.006

Humphries, T.J., \& Kessler, C. M. (2015). Managing chronic pain in adults with haemophilia: current status and call to action. Haemophilia, 21, 41-51. DOI: 10.1111/hae.12526

Humphries, T.J., \& Kessler, C. M. (2016). Pain in haemophilia: are we listening? Haemophilia, 22, 175178. DOI: $10.1111 /$ hae.12855

Jensen, M.P., Nielson, W.R., \& Kerns, R.D. (2003a). Toward the development of a motivational model of pain self-management. Journal of Pain, 4, 477-492. DOI: 10.1067/S1526-5900(03)00779-X

Jensen, M.P., Nielson, W.R., Turner, J.A., Romano, J.M., \& Hill, M.L. (2003b). Readiness to self-manage pain is associated with coping and with psychological and physical functioning among patients with chronic pain. Pain, 104, 529-537. DOI: 10.1016/S0304-3959(03)00092-7

Jensen, M.P., Nielson, W.R., Turner, J.A., Romano, J.M., \& Hill, M.L. (2004). Changes in readiness to selfmanage pain are associated with improvement in multidisciplinary pain treatment and pain coping. Pain, 111, 84-95. DOI: 10.1016/j.pain.2004.06.003

Kenny, D.A. (1975). Cross-lagged panel correlation: a test for spuriousness. Psychological Bulletin, 82, 887-903.

Kenny, D.A. (2014). Cross-Lagged Panel Design. John Wiley \& Sons, Ltd. Wiley StatsRef: Statistics Reference Online. http://onlinelibrary.wiley.com/doi/10.1002/9781118445112.stat06464/full

Kerns, R.D. \& Rosenberg, R. (2000). Predicting responses to self-management treatments for chronic pain: application of the pain stages of change model. Pain, 84, 49-55.

Kerns, R.D., Rosenberg, R., Jamison, R.N., Caudill, M.A., \& Haythornwaite, J. (1997). Readiness to adopt a self-management approach to chronic pain: the Pain Stages of Change Questionnaire (PSOCQ). Pain, 72, 227-234.

Kline, R.B. (2011). Principles and Practice of Structural Equation Modeling: Fourth Edition. New York: Guilford Press.

Kranz, D., Bollinger, A., \& Nilges, P. (2010). Chronic pain acceptance and affective well-being: A coping perspective. European Journal of Pain, 14, 1021-1025. DOI:10.1016/j.ejpain.2010.03.010

Lauwerier, E., Caes, L., Van Damme, S., Goubert, L., Rosseel, Y., \& Crombez, G. (2015). Acceptance: What's in a name? A content analysis of acceptance instruments in individuals with chronic pain. The Journal of Pain, 16, 306-317. DOI: 10.1016/j.jpain.2015.01.001

Llabre, M.M., Spitzer, S. B., Saab, P. G., Ironson, G. H., \& Schneiderman, N. (1991). The reliability and specificity of delta versus residualized change as measures of cardiovascular reactivity to behavioral challenges. Psychophysiology, 28, 701-711. 
McCracken, L.M. \& Eccleston, C. (2003). Coping or acceptance: what to do about chronic pain? Pain, 105, 197-204.

McCracken, L.M., Eccleston, C. (2006). A comparison of the relative utility of coping and acceptancebased measures in a sample of chronic pain sufferers. European Journal of Pain 10, 23-29.

McCracken, L.M., Vowles, K.E., \& Eccleston, C. (2004). Acceptance of chronic pain: component analysis and a revised assessment method. Pain, 107, 159-166. DOI: 10.1016/j.pain.2003.10.012

McCracken, L.M., Vowles, K.E., \& Gauntlett-Gilbert, J. (2007). A prospective investigation of acceptance and control-oriented coping with chronic pain. Journal of Behavioral Medicine, 30, 339-349.

DOI: 10.1007/s10865-007-9104-9

Newsom, J.T. (2016). Cross-lagged Panel Analysis. In S. Krauss Whitbourne (Ed.), The Encyclopedia of Adulthood and Aging. Wiley. http://onlinelibrary.wiley.com/doi/10.1002/9781118521373.wbeaa250/full

Preacher, K.J., Wichman, A.L., MacCallum, R.C., \& Briggs, N.E. (2008). Latent growth curve modeling (No. 157). London: Sage.

Riley, R. R., Witkop, M., Hellman, E., \& Akins, S. (2011). Assessment and management of pain in haemophilia patients. Haemophilia, 17, 839-845. DOI: 10.1111/j.1365-2516.2011.02567.x

Rodriguez-Merchan, E.C. (2012). Prevention of the musculoskeletal complications of hemophilia. Advances in Preventive Medicine, Epub 201271. DOI: 10.1155/2012/201271

Royston, P. (2004). Multiple imputation of missing values. Stata Journal, 4, 227-241.

Tabachnick, B.G. \& Fidell, L.S. (1996). Using Multivariate Statistics. London: Harper Collins.

Van Damme, S., Crombez, G., \& Eccleston, C. (2008). Coping with pain: a motivational perspective. Pain, 139, 1-4. DOI:10.1016/j.pain.2008.07.022

Vowles, K.E., McCracken, L.M., McLeod, C., \& Eccleston, C. (2008). The chronic pain acceptance questionnaire: Confirmatory factor analysis and identification of patient subgroups. Pain, 140, 284-291.

Vowles, K.E., Sowden, G., \& Ashworth, J. (2014). A comprehensive examination of the model underlying acceptance and commitment therapy for chronic pain. Behavior Therapy, 45, 390-401.

Wetherell, J.L., Afari, N., Rutledge, T., Sorrell, J.T., Stoddard, J.A., Petkus, A.J., Solomon, B.C., Lehman, D.H., Liu, L., Lang, A.J. \& Atkinson, J.H. (2011). A randomized, controlled trial of acceptance and commitment therapy and cognitive-behavioral therapy for chronic pain. Pain, 152, 2098-2107.

Wicksell, R. K., Olsson, G. L., \& Melin, L. (2009). The Chronic Pain Acceptance Questionnaire (CPAQ)-further validation including a confirmatory factor analysis and a comparison with the Tampa Scale of Kinesiophobia. European Journal of Pain, 13, 760-768.

DOI:10.1016/j.ejpain.2008.09.003

Witkop, M., Lambing, A., Divine, G., Kachalsky, E., Rushlow, D., \& Dinnen, J. (2012). A national study of pain in the bleeding disorders community: a description of haemophilia pain. Haemophilia, 18, e115-e119. DOI: 10.1111/j.1365-2516.2011.02709.x 


\section{Appendix 1: Sample Characteristics}

Baseline descriptive statistics for the initial and present samples are given in Table A1. The two samples were very similar demographically and clinically. The present sample had lower baseline contemplation [mean 3.05 (SD 0.65)] than the remainder of the initial sample [mean 3.25 (SD 0.62), $\mathrm{T}_{(193)}$ $=2.11, p=0.036]$ but did not differ in age, hemophilia type or severity, or any other baseline measures.

Table A1. Baseline descriptive statistics for initial and present samples

\begin{tabular}{|c|c|c|}
\hline & Initial sample & Present sample \\
\hline $\mathrm{N}$ & 209 & 78 \\
\hline Mean age (SD, range) & $49.5(12.8,20-84)$ & $51.4(12.5,26-81)$ \\
\hline \multicolumn{3}{|l|}{ Type of disorder } \\
\hline Hemophilia A & 165 (78.9\%) & 62 (79.5\%) \\
\hline Hemophilia B & $39(18.7 \%)$ & $14(17.9 \%)$ \\
\hline Not known & $5(2.4 \%)$ & $2(2.6 \%)$ \\
\hline \multicolumn{3}{|l|}{ Hemophilia severity } \\
\hline Mild & $46(22.0 \%)$ & $17(21.8 \%)$ \\
\hline Moderate & $24(11.5 \%)$ & $10(12.8 \%)$ \\
\hline Severe & $132(63.2 \%)$ & $49(62.8 \%)$ \\
\hline Not known & $7(3.3 \%)$ & $2(2.6 \%)$ \\
\hline \multicolumn{3}{|l|}{ Marital status } \\
\hline Single & $41(19.6 \%)$ & $12(15.4 \%)$ \\
\hline Married/cohabiting & $141(67.5 \%)$ & $55(70.5 \%)$ \\
\hline Divorced/separated & $22(10.5 \%)$ & $8(10.3 \%)$ \\
\hline Other & $5(2.4 \%)$ & $3(3.8 \%)$ \\
\hline \multicolumn{3}{|l|}{ Educational level } \\
\hline High school only ${ }^{1}$ & $74(35.4 \%)$ & $28(35.9 \%)$ \\
\hline Post-16 education ${ }^{2}$ & $72(34.4 \%)$ & $34(43.6 \%)$ \\
\hline Higher education ${ }^{3}$ & $57(27.3 \%)$ & $13(16.7 \%)$ \\
\hline Other/not known & $6(2.9 \%)$ & $3(3.9 \%)$ \\
\hline \multicolumn{3}{|c|}{ Mean (SD) baseline scores } \\
\hline Precontemplation & $2.86(0.74)$ & $2.85(0.74)$ \\
\hline Contemplation & $3.17(0.64)$ & $3.05(0.65)$ \\
\hline Action/maintenance & $3.08(0.62)$ & $3.14(0.60)$ \\
\hline Active coping & $2.44(1.12)$ & $2.26(1.14)$ \\
\hline Activity engagement & $39.77(11.00)$ & $40.23(10.75)$ \\
\hline Pain willingness & $25.16(9.34)$ & 25.37 (9.08) \\
\hline Acceptance total & $64.93(17.10)$ & $65.61(16.51)$ \\
\hline
\end{tabular}

Notes to table S1:

1. Left school at 16 years

2. High school to 18 years or Further Education

3. University undergraduate or postgraduate study 


\section{Appendix 2: Structural Equation Modelling}

Latent change analyses (LCA) were used to examine patterns of change in key measures. These analyses examine the intercept (where a participant starts) and the slope (the rate and type of change) across time points (Preacher et al., 2008). For each measure we tested a series of models with different combinations of parameters restricted. This meant initially restricting the mean and variance of the intercept and slope (assuming all participants have the same mean and variance on the intercept and slope), then successively unrestricting the intercept mean, intercept variance, slope mean, slope variance and finally the covariance between the intercept and slope

Table A2 gives fit indices and other statistics for the optimal model for each measure. Active coping had a positive slope, showing significant change over time. The slope co-varied with the intercept, with higher intercepts associated with shallower slopes. The strongest models for the other measures were those with the slope restricted, indicating little change over time. Pain willingness and activity engagement showed high variance around the intercept mean, indicating that participants started at different point on the scales.

Structural equation modelling was then used to test models of hypothesized change processes in which changes were represented by latent variables each based on measured variables at two time points. For hypothesis 1 , we tested models in which early changes in precontemplation and contemplation were used to predict later changes in active coping, action-maintenance and activity engagement. The first of these included all those variables, which were then successively removed in a series of simpler models that were considered further only if they did not contain variables with negative error variances, indicating model mis-specification ('Heywood Cases'; Kline, 2011).

For hypotheses 2 and 3, one model was used to test each hypothesis. In one, the pathway from early change in activity engagement to later change in pain willingness was tested in a model with later change in activity engagement and early change in pain willingness included as covariates. In the other, the pathway from early change in pain willingness to later change in activity engagement was tested in a model with later change in pain willingness and early change in activity engagement included as covariates.

Table A3 gives fit indices for models with no negative error variances, along with the values these should be at least 'close to' for a good fit between model and data (Hu \& Bentler, 1999). Model 1 was the full model tested for hypothesis 1 , and Model 2 was a simpler model in which early changes in precontemplation and contemplation were used to predict later changes in just active coping. For both models 1 and 2, $X^{2}$ was significant, indicating differences between the data and the model. However, the $X^{2}$ statistic is known to be over-sensitive to sample size (Gerbing \& Anderson, 1985) so that even modest sample sizes can lead to misleadingly significant values, wrongly indicating that a model should be rejected (lacobucci, 2010).

More importantly, $X^{2}$ was over eight times larger for Model 1 than Model 2, indicating Model 2 was a much better fit to the data. For Model 2, the other three fit indices were all the correct side of the recommended values, whereas for Model 1 the fit indices were within the recommended limits for one indicator (SRMR) but outside the recommended limits for the other two (RMSEA and CFI). Model 2 therefore appeared a much better fit, and is illustrated in Fig. A1, which shows significant pathways 
from early changes in both precontemplation (-0.472) and contemplation (0.48) to later change in active coping

Table A3 also gives fit indices for models 3 and 4, which were tests of hypotheses 2 and 3. For both models, $X^{2}$ was non-significant, indicating good fits to the data, and both models were also the correct side of the recommended value for RMSEA and CFI. The fit indices for the two models were the same for SRMR and CFI, but were marginally better for model 3 for $X^{2}$ and RMSEA. Model 3 therefore appeared a better fit, and is illustrated in Fig. A2. However, the key hypothesized pathways were nonsignificant in both models.

\section{References}

Gerbing, D.W., \& Anderson, J.C. (1985). The effects of sampling error and model characteristics on parameter estimation for maximum likelihood confirmatory factor analysis. Multivariate Behavioral Research, 20, 255-271.

Hu, L., \& Bentler, P.M. (1999). Cutoff criteria for fit indexes in covariance structure analysis: Conventional criteria versus new alternatives. Structural Equation Modeling: A Multidisciplinary Journal, 6, 1-55.

lacobucci, D. (2010). Structural equation modeling: Fit Indices, sample size, and advanced topics. Journal of Consumer Psychology, 20, 90-98.

Kline, R.B. (2011). Principles and Practice of Structural Equation Modeling: Fourth Edition. New York: Guilford Press.

Preacher, K.J., Wichman, A.L., MacCallum, R.C., \& Briggs, N.E. (2008). Latent growth curve modeling (No. 157). London: Sage. 
Table A2. Latent growth analysis; model fit indices, intercept mean and variance, slope mean and variance, for all variables

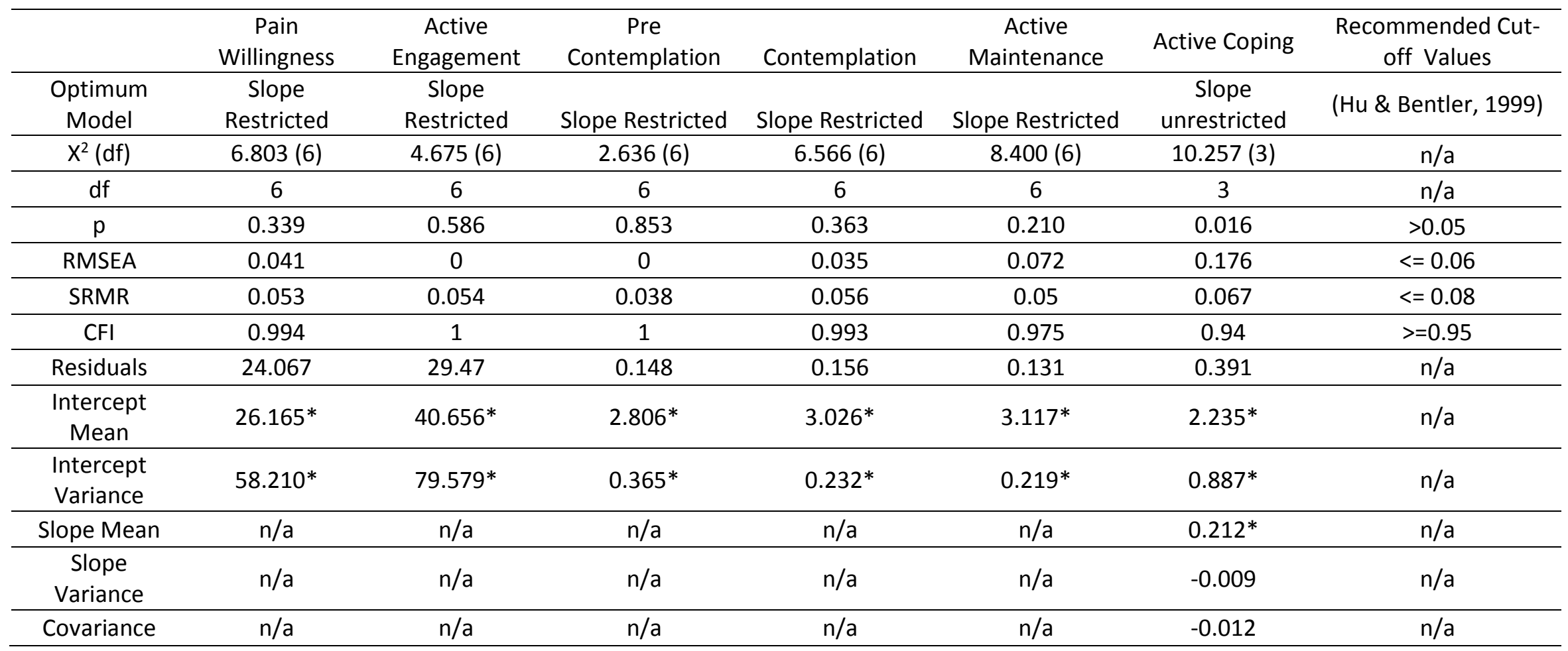

Notes:

$X^{2}=$ Chi Squared; $d f=$ degrees of freedom; $p=$ probability; $n / a=$ not applicable

$* p<.05$ 
Table A3. Fit indices and recommended cut offs for structural equation models of change processes

\begin{tabular}{cccccc}
\hline & \multicolumn{2}{c}{ Hypothesis 1 } & Hypothesis 2 & Hypothesis 3 & $\begin{array}{c}\text { Recommended } \\
\text { values }\end{array}$ \\
\hline & Model 1 & Model 2 & Model 3 & Model 4 & $\begin{array}{c}\text { (Hu \& Bentler, } \\
\text { 1999) }\end{array}$ \\
\hline$X^{2}(\mathrm{df})$ & 64.984 & 7.878 & 2.500 & 2.542 & $\mathrm{n} / \mathrm{a}$ \\
\hline $\mathrm{df}$ & 5 & 6 & 2 & 2 & $\mathrm{n} / \mathrm{a}$ \\
\hline $\mathrm{P}$ & $<.001$ & $<.001$ & 0.287 & 0.281 & $>0.05$ \\
\hline RMSEA & 0.143 & 0.063 & 0.057 & 0.059 & $<=0.06$ \\
\hline SRMR & 0.056 & 0.030 & 0.010 & 0.010 & $<=0.08$ \\
\hline CFI & 0.899 & 0.989 & 0.998 & 0.998 & $>=0.95$ \\
\hline
\end{tabular}

Notes: $X^{2}=$ Chi Squared; $d f=$ degrees of freedom; $p=$ probability; RMSEA=root mean squared error of approximation; $\mathrm{SRMR}=$ standardized root mean squared residual; $\mathrm{CFI}=\mathrm{Comparative} \mathrm{Fit} \mathrm{Index;}$ n/a=not applicable. 
Fig. A1. Path diagram of the best-fitting structural equation model for hypothesis 1

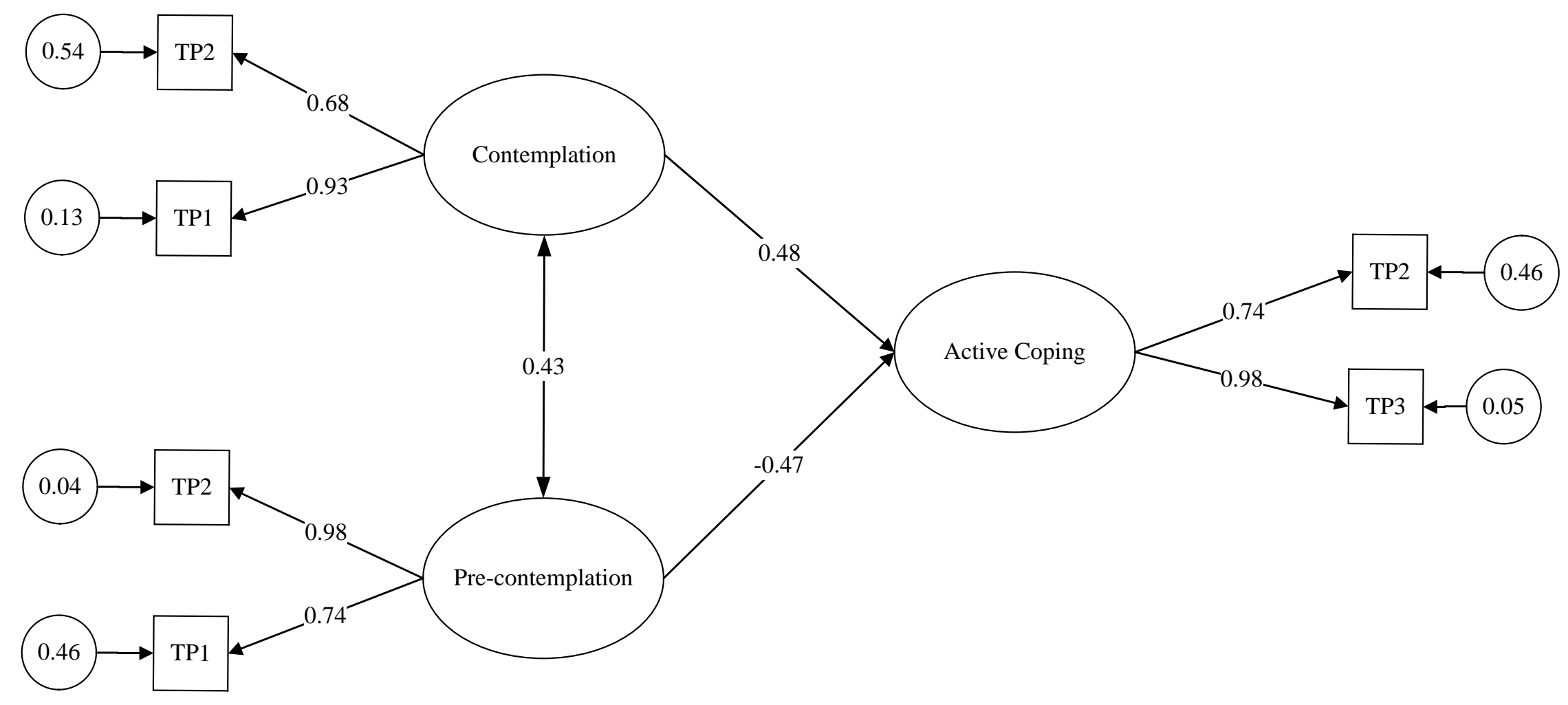

Note: $\mathrm{TP}=$ time point 
Fig.A2. Path diagram of the best fitting structural equation model for hypotheses 2 and 3

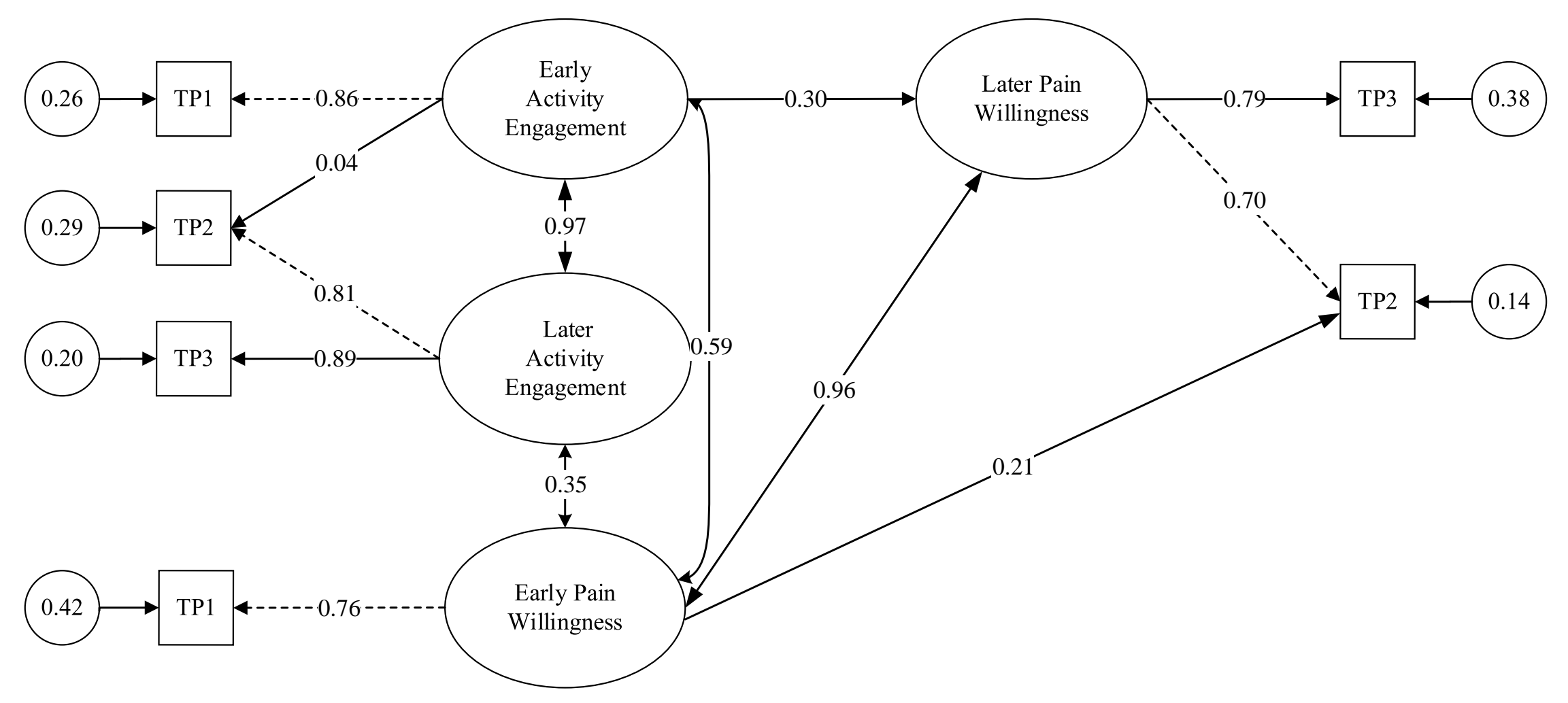

Note: $\mathrm{TP}=$ time point. 